\title{
Preoperative gynecology conference: the impact on resident management of surgical patients
}

\author{
Amanda B. Murchison, MD, ${ }^{1}$ Eduardo Lara-Torre, MD, ${ }^{1}$ Patrice M. Weiss, MD ${ }^{1}$
}

Key Words: gynecology, preoperative conference, surgical procedure

\begin{abstract}
:
Objective: To determine if a preoperative conference impacts the resident recommended surgery on gynecology patients seen in continuity clinics.

Study Design: A twice monthly preoperative conference was initiated in January of 2009 where residents presented their proposed surgical intervention. A retrospective review of the first 100 preoperative conference submission forms was performed and analysis made on how often the type or route of surgery was changed based on conference discussion and if further workup or tests were requested prior to scheduling surgery.
\end{abstract}

Results: Discussion of patients through a preoperative conference venue resulted in a change in surgical management of $36 \%$ of patients, and further medical management prior to surgery was recommended in $29 \%$.

Conclusions: A preoperative gynecology conference does impact the chosen surgery for resident patients. This venue may be a valuable tool for teaching residents optimization of the preoperative evaluation and selection of the appropriate surgical intervention.

${ }^{1}$ Virginia Tech Carilion School of Medicine, Department of Obstetrics and Gynecology, Roanoke, VA

Disclosure: None of the authors have a conflict of interest.

\section{Introduction}

Currently, there are new challenges in training residents to be competent in the operating room. Not only are we faced with resident work hour restrictions, but also increasing advances in surgical technology, leaving residents a wider range of surgical techniques that must be mastered. ${ }^{1}$ Many obstetrics and gynecology (ob/gyn) residency programs have established simulation programs to help residents become more proficient with surgical techniques before they encounter real patients. ${ }^{2}$ However, there is little published literature on teaching residents how to choose the most appropriate surgical technique for each individual patient. A twice monthly preoperative conference was initiated in the ob/gyn residency program at Carilion Clinic in January of 2009. All generalists faculty who supervise the resident clinic were expected to attend. The primary objective of this conference was to improve patient care by scheduling the most appropriate gynecologic surgical

Please cite this paper as: Murchison AB, Lara-Torre E, Weiss PM, Preoperative gynecology conference: the impact on resident management of surgical patients. Proc Obstet Gynecol. 2012 May 2(3): Article 14 [ 3 p.]. Available from: http://ir.uiowa.edu/pog/. Free full text article.

Corresponding author: Amanda Murchison, MD. 1906 Belleview Avenue, Roanoke, VA 24014. Cell 540597-5640. Fax 540-983-1192. abmurchison@carilionclinic.org .

This is an Open Access article distributed under the terms of the Creative Commons Attribution 3.0 Unported License (http://creativecommons.org/licenses/by/3.0), which permits unrestricted use, distribution, and reproduction in any medium, provided the original work is properly cited. 
procedure for each individual patient. Secondary objectives were to improve resident education by highlighting and discussing the workup of gynecologic conditions requiring surgery and the thought process of determining the most appropriate surgery for each patient. Competencies addressed through a preoperative conference include patient care, practice-based learning, system-based practice and professionalism. The objective of this study was to determine if a preoperative conference impacts the chosen surgery for resident gynecology patients. If a significant impact is seen, then this may be a valuable tool for teaching residents the appropriate workup of gyn patients, helping to ensure the appropriate surgical intervention for each patient.

\section{Materials and Methods}

An analytic, retrospective, interventive study was performed after IRB exemption was obtained. The first 100 preoperative conference submission forms were reviewed. These forms were filled out by the residents prior to presenting the patients at the preoperative conference. The form lists the proposed surgery submitted by the resident and the final decision by the pre-op conference consensus as well as any additional tests or information needed prior to approval for scheduling patients for surgery. Analysis was performed on how often the type or route of surgery was changed based on conference discussion and if further workup or tests were requested prior to scheduling the surgery; binomial proportions were used with a $95 \%$ upper and lower confidence interval $(\mathrm{Cl})$.

\section{Results}

Analysis of the first 100 preoperative form submissions was performed. Five of the forms were incompletely filled out and therefore were not included. The remaining 95 forms showed that a change in the planned surgical management of patients occurred $36 \%$ of the time $(95 \% \mathrm{Cl}$ $0.26-0.46)$. In addition, in $29 \%$ of cases further workup or additional medical management was recommended prior to scheduling the patient for a surgical intervention (Table 1, 95\% Cl 0.20-0.39).

Table 1: Patients who required further workup or management prior to surgery

\begin{tabular}{lc}
\hline Further workup indicated & Number of patients \\
\hline Mammogram & 6 \\
Laboratory study & 6 \\
CT scan & 1 \\
Medical clearance/optimization & 7 \\
Pap smear & 8 \\
Pelvic ultrasound & 3 \\
Endometrial biopsy & 3 \\
Urodynamics & 1 \\
Office visit with chief resident & 4 \\
\hline
\end{tabular}




\section{Comments}

Starting a resident preoperative gynecology conference resulted in a surgical management change $36 \%$ of the time. Obstetrics and gynecology residents are increasingly confronted with mastering a broader range of surgical techniques. ${ }^{3}$ Many tools now exist to assist in evaluating a resident's surgical competency in the operating room. ${ }^{4}$ However, there are no published tools for teaching and evaluating a resident's ability to appropriately work up a surgical patient, including selecting the most appropriate surgical technique. Discussion of resident gynecology patients through a preoperative conference has allowed for identification of topics that our residents need highlighted. It has provided our department with the opportunity to discuss the evaluation and management of surgical patients with our residents while addressing the competencies of patient care, practiced-based learning, systembased practice and professionalism. Our study did not evaluate whether a change in workup or intervention affected patient outcomes or if there were any increased costs associated with these changes, both of which would be interesting areas for future studies.

\section{References}

1. Goff $B A$. Changing the paradigm in surgical education. Obstet Gynecol. 2008 Aug;112(2 Pt 1):328-32.

PubMed PMID: 18669731. http://dx.doi.org/10.1097/AOG.0b01 3e3181802163

2. Geoffrion R. Standing on the shoulders of giants: contemplating a standard national curriculum for surgical training in gynaecology. J Obstet Gynaecol Can. 2008 Aug;30(8):684-95. Review. PubMed PMID: 18786291.

3. Pulliam SJ, Berkowitz LR. Smaller pieces of the hysterectomy pie: current challenges in resident surgical education. Obstet Gynecol. 2009 Feb;113(2 Pt 1):395-8.

PubMed PMID: 19155911. DOI: 10.1097/AOG.0b013e3181955011

4. Chou B, Bowen CW, Handa VL. Evaluating the competency of gynecology residents in the operating room: validation of a new assessment tool. Am J Obstet Gynecol. 2008 Nov;199(5):571.e1-5. Epub 2008 Sep 16. PubMed PMID: 18799153.

http://dx.doi.org/10.1016/j.ajog.2008 06.082 